\title{
EXECUTIVE FUNCTIONING AND ALCOHOL BINGE DRINKING IN UNIVERSITY STUDENTS
}

\author{
Authors: María Parada, Montserrat Corral, Nayara Mota, Alberto Crego, Socorro Rodríguez \\ Holguín, Fernando Cadaveira \\ Department of Clinical Psychology and Psychobiology, University of Santiago de Compostela, Spain
}

This is the peer reviewed version of the following article: Parada M; Corral M; Mota N; Crego A; Rodríguez Holguín S; Cadaveira F (2012). Executive functioning and alcohol binge drinking in university students. Addictive Behaviors, 37, 167-172 doi:10.1016/j.addbeh.2011.09.015. This article may be used for non-commercial purposes in accordance with Elsevier Ltd. Conditions for Use of Self-Archived Versions. 


\title{
Executive functioning and alcohol binge drinking in university students
}

María Parada, Montserrat Corral, Nayara Mota, Alberto Crego, Socorro Rodríguez Holguín, Fernando Cadaveira

Department of Clinical Psychology and Psychobiology, University of Santiago de Compostela, Spain Corresponding author: María Parada. Departamento de Psicoloxía Clínica e Psicobioloxía, Facultade de Psicoloxía, Campus Vida, 15782, Santiago de Compostela, Galicia, Spain. Tel.: + 34981563100 ; fax: + 34981 528071. E-mail address: maria.parada@usc.es

\begin{abstract}
Background: Binge drinking (BD) is prevalent among college students. Studies on alcoholism have shown that the prefrontal cortex is vulnerable to the neurotoxic effects of alcohol. The prefrontal cortex undergoes both structural and functional changes during adolescence and young adulthood. Sex differences have been observed in brain maturation and in alcohol-induced damage. The objective of the present study was to analyze the relationship between $\mathrm{BD}$ and cognitive functions subserved by the prefrontal cortex in male and female university students. Methods: The sample comprised 122 undergraduates (aged 18 to 20 years): 62 BD (30 females) and 60 non-BD (29 females). Executive functions were assessed by WMS-III (Backward Digit Span and Backward Spatial Span), SOPT (abstract designs), Letter Fluency (PMR), BADS (Zoo Map and Key Search) and WCST-3. Results: BD students scored lower in the Backward Digit Span Subtest and generated more perseverative responses in the SOPT In relation to interaction BD by sex, BD males scored lower in the Backward Digit Span test than BD females and non-BD males. Conclusions: BD is associated with poorer performance of executive functions subserved by the dorsolateral prefrontal cortex. The results do not support enhanced vulnerability of women to alcohol neurotoxic effects. These difficulties may reflect developmental delay or frontal lobe dysfunction.
\end{abstract}


Keywords: Binge drinking, Alcohol, University students, Adolescent development, Executive functions, Prefrontal cortex

\section{Introduction}

Binge drinking (BD), or heavy episodic drinking, is becoming increasingly frequent among university students in different countries, even in Mediterranean countries traditionally characterized by regular and moderate alcohol intake (Courtney \& Polich, 2009; Vicki, Kuntsche, \& Gmel, 2010). BD is characterized by the intake of large amounts of alcohol within a short period and on a few days a week. Several studies have indicated that intermittent alcohol consumption may constitute a greater risk to neurocognitive functioning than regular alcohol consumption (Stephens \& Duka, 2008). In addition, the adolescent brain may be more vulnerable to the effects of alcohol because of the extensive neuromaturational processes that occur during adolescence, when significant restructuring of the brain takes place (Casey, Jones, \& Hare, 2008; Crews \& Boettiger, 2009; Guerri \& Pascual, 2010).

At a neuropsychological level, adolescence is the period when most complex cognitive abilities are acquired. Significant improvements are observed in executive skills such as planning, problemsolving, working memory and inhibitory control at this stage of development (Conklin, Luciana, Hooper, \& Yarger, 2007; Luciana \& Nelson, 2002; Luna, Padmanabhan, \& O'Hearn, 2010; Rubia et al., 2000; Salatas-Waters, 1982; Welsh, Pennington, \& Groisser, 1991). Moreover, it has been suggested that cognitive development throughout adolescence is associated with progressively greater efficiency of cognitive control capacities, which appear to depend on maturation of the prefrontal cortex (Yurgelun-Todd, 2007). This is structurally one of the last cortical regions to reach full development (Blakemore \& Choudhury, 2006; Gogtay et al., 2004; Sowell, Thompson, Tessner, \& Toga, 2001).

Animal studies have shown the sensitivity of the adolescent rat brain to the effects of alcohol. Intermittent administration of ethanol during adolescence induces prefrontal cortex damage (Crews, Braun, Hoplight, Switzer, \& Knapp, 2000; Pascual, Blanco, Cauli, Miñarro, \& Guerri, 2007), changes in dopaminergic and glutamatergic neurotransmission (Pascual, Boix, Felipo, \& Guerri, 2009) and short and long-lasting cognitive and behavioral deficits (Obernier, White, Swartzwelder, \& Crews, 2002; Pascual et al., 2007; Schulteis, Archer, Tapert, \& Frank, 2008).

In humans, it has been found that young people with Alcohol Use Disorder (AUD) have a smaller prefrontal cortex volume and perform less well in neuropsychological attention and working memory tasks than control subjects (De Bellis et al., 2005; Medina et al., 2008; Tapert, Baratta, Abrantes, \& 
Brown, 2002; Tapert \& Brown, 1999). Activation of the prefrontal cortex is also lower in subjects suffering from AUD than in control subjects during a working memory task (Caldwell et al., 2005; Tapert et al., 2001; Tapert et al., 2002).

To date, few studies have been carried out to investigate the effects of $\mathrm{BD}$ on executive functions related to prefrontal cortex in the general adolescent population. Hartley, Elsabagh, and File (2004) compared the neuropsychological performance of 27 university students distributed in two groups according to their pattern of alcohol consumption: 14 BD (who consumed 10 or more alcoholic drinks on a single occasion) and 13 abstainers. BD subjects performed less well in attention and planning tasks. Performance was similar in men and women. In addition, when the BD group was divided on the basis of the amount of alcohol consumed (more than 18 drinks a week and less than 18 drinks a week), both groups performed similarly in the tests, which suggests that the differences between the $\mathrm{BD}$ and the abstainers were related to the pattern of alcohol consumption rather than to the amount of alcohol consumed.

In a second study (García-Moreno, Expósito, Sanhueza, \& Angulo, 2008; García-Moreno, Expósito, Sanhueza, \& Gil, 2009) university students were divided into three groups: abstainers, subjects with moderate consumption of 4 or more alcoholic drinks on a single occasion, and subjects with abusive consumption of 5 or more drinks on one occasion. The subjects with a moderate or abusive pattern of alcohol consumption showed poorer performance in tasks related to the dorsolateral prefrontal cortex functioning.

Finally, Nederkoorn, Baltus, Guerrieri, and Wiers (2009) evaluated the performance of 64 university students in an adapted version of the Stop Signal Task. The students were classified as light or heavy drinkers according to their alcohol consumption (upper/lower threshold of 11.5 units for females and 12.5 units for males). The authors found no differences in response inhibition between light and heavy drinkers, but heavy drinking females showed stronger response inhibition deficits than other groups.

Studies with social drinkers from a wider age group (18-35 years) found that the young social drinkers with a BD pattern of alcohol consumption experienced more difficulties related to visuospatial working memory (Weissenborn \& Duka, 2003) and inhibitory control (Townshend \& Duka, 2005) than social drinkers who did not follow this pattern of consumption. Binge drinking women performed less well than other groups on visuospatial working memory and flexibility cognitive tasks (Scaife \& Duka, 2009; Townshend \& Duka, 2005). These results, together with reported by Hartley et al. (2004), show that the difficulties experienced by BD are possibly due to the peaks in consumption rather than to the amounts ingested, and indicate the need for further studies on this topic. 
In addiction, the impact of other associated risk factors (such as psychiatric comorbility, family history of alcoholism or cannabis consumption) has not controlled in all cases and this may limit the interpretation of results. Finally, only few studies have taken into account sex differences.

The issue of increased vulnerability of women to the neurotoxic effects of alcohol is still controversial (Hommer, 2003; Oscar-Berman \& Marinkovic, 2007 for reviews). Several studies have reported sex differences in the sensitivity to alcohol-induced brain damage in alcoholics (Acker, 1986; Hommer, Momenan, Kaiser, \& Rawlings, 2001; Mann et al., 2005), AUD adolescents (Caldwell et al., 2005; Medina et al., 2008) and young social drinkers (Scaife \& Duka, 2009; Townshend \& Duka, 2005). However, other studies with alcoholics did not find any such differences (Glenn \& Parsons, 1992; Sullivan, Fama, Rosenbloom, \& Pfefferbaum, 2002).

The first aim of the present study was to investigate the association between BD and executive skills in university students. Because of the important degree of maturation of the dorsolateral prefrontal cortex during adolescence, and taking into account the greater vulnerability of the frontal lobes to the neurotoxic effects of alcohol (Oscar-Berman \& Marinkovic, 2007 for review), it is possible that this brain region may be particularly susceptible to damage during adolescence. We hypothesize that BD subjects will perform less well than non-BD subjects in tasks that evaluate functions associated with the dorsolateral prefrontal cortex. Secondly, to determine whether the relationship between BD and cognitive functioning is modulated by sex. Our hypothesis is those females are more vulnerable to neurocognitive effects of BD.

\section{Material and methods}

\subsection{Sample}

Participants were selected through an anonymous questionnaire administered in-class to first-year students at the University of Santiago de Compostela (Spain) (Caamaño-Isorna, Corral, Parada, \& Cadaveira, 2008). The questionnaire included the Galician version of Alcohol Use Disorders Identification Test (AUDIT) (Varela, Braña, Real, \& Rial, 2005) and questions related to the use of alcohol (speed of consumption, age of onset on alcohol consumption, etc.). The classification criteria, as detailed in Crego et al. (2010), are based on their responses to two questions: the third question of the AUDIT (How often do you have six or more drinks on a single occasion? Never/Less than monthly/Monthly/Weekly/Daily or almost daily) and one question pertaining to the speed of consumption (drinks per hour). Taking into account that in Spain one SAD contains $10 \mathrm{~g}$ of alcohol, the BD group comprised those subjects who consumed 6 or more alcoholic drinks on a single occasion, one or more times per month, and drank 3 or more drinks per hour. The non-BD group was 
composed of those students who never consumed 6 or more alcoholic drinks on a single occasion or less than once per month and drank 2 or less drinks per hour.

Sporadic cannabis users were not excluded from the study. A high correlation between alcohol and cannabis use in adolescents and in university students has been consistently reported (Chun et al., 2010; Degenhardt, Hall, \& Lynskey, 2001; Falk, Yi, \& Hiller-Sturmhöfel, 2008). Similarly, in the present study the percentage of cannabis users was significantly higher in the BD group than in the non-BD group.

The exclusion criteria, assessed through a semi-structured interview, were as follows: a score above 90 in the Global Severity Index (GSI) of the SCL-90-R (Degoratis, 1983) or in at least two of the symptomatic dimensions, personal history of neurological or relevant systemic disease, regular consumption of cannabis or other illegal drugs, alcohol abuse/dependence according to the DSM-IV criteria, personal and/or family history of major mental disorder and history of alcoholism in firstdegree relatives. Finally, 122 participants were selected for neuropsychological assessment: 62 binge drinkers (32 males and 30 females) and 60 non-binge drinkers (31 males and 29 females). The sociodemographic, clinical and alcohol use pattern characteristics are shown in Table 1.

\section{Table 1}

Participants were asked to abstain from consuming drugs and alcohol within $24 \mathrm{~h}$ prior to neuropsychological assessment. All of the individuals signed an informed consent form and received financial compensation for their participation in the study (15€). The evaluation was completed by psychological specialists in neuropsychology who were blind to the participants' condition.

\subsection{Material}

Dorsolateral prefrontal functions were assessed by the following tests:

Backward Digit Span (Wechsler Memory Scale-III, WMS-III) (Wechsler, 1997): Sequences of numbers are read out to participants who are asked to repeat them, in reverse order. The numbers are increased in length by one digit from trial to trial; the number of digits in the longest sequence recalled correctly is recorded. This test assesses verbal working memory.

Backward Spatial Span (WMS-III) (Wechsler, 1997): The examiner taps cubes in sequences of increasing length, and immediately after participants are required to reproduce each sequence, in reverse order. This test evaluates spatial working memory.

The Digit Span Backward and Spatial Span Backward tests are frequently used to assess the executive component of the working memory, which depends on the integrity of a network that includes the 
dorsolateral prefrontal cortex (Baddeley, 2003).

Self-Ordered Pointing Test, abstract design version (SOPT) (Petrides \& Milner, 1982): The subject is presented with a booklet consisting of different pages, each of which shows a series of abstract drawings (hard to verbalize designs). The stimuli are repeated on all pages in each test, but the position changes at random from page to page. The task is to point to one design on each page, without repeating previously indicated designs. The test consists of 4 trials with six, eight, ten and twelve stimuli. For each participant, the total number of errors and the perseverative errors (errors that occurred as a result of pointing to the same item that was chosen on the immediately preceding page) are recorded. The SOPT assesses planning and self-monitoring aspects of working memory. The performance is associated with scores on some other measures of executive function and working memory (Ross, Hanouskova, Giarla, Calhoun, \& Tucker, 2007). Several investigations including nonhuman primate lesion studies (Petrides, 1991; Petrides, 1995) and human imaging studies (Curtis, Zald, \& Pard, 2000; Petrides, Alivisatos, Evans, \& Meyer, 1993) relate the importance of dorsolateral prefrontal cortex, specifically mid-dorsolateral regions, to successful performance of this task.

Letter Fluency (Artiola I Fortuny, Hermosillo-Romo, Heaton, \& Pardee, 1999): The subject is asked to say as many words as possible that begin with a certain letter $(\mathrm{P}, \mathrm{M}, \mathrm{R})$ in $1 \mathrm{~min}$. The total number of correct words was recorded. This task evaluates spontaneous cognitive flexibility, i.e. the capacity to produce a flow of ideas or of items in response to simple instructions. Studies of brain lesions (Henry \& Crawford, 2004) and neuroimaging studies have related this process to functioning of the prefrontal cortex, especially the left dorsolateral region (Frith, Friston, Liddle, \& Frackowlak, 1991; Gourovitch et al., 2000; Phelps, Hyder, Blamire \& Shulman, 1997).

Zoo Map subtest (Behavioural Assessment of Dysexecutive Syndrome, BADS (Wilson et al, 1996). This is a planning test in wich the subjects has to indicate on a map provided of a zoo, the route they would take to visit six of twelve possible locations. There were two versions of the trial, with the same aim but with different instructions. The first trial consist of a "high demand" version of the task. Participants are given a zoo map and a set of instructions relating to places they have to visit and rules to be observed. In the second trial, or "low demand" version, the participant is simply required to follow the instructions to reach the twelve locations and to produce an error-free performance. Comparison of the performance of the trials enables assessment of the planning ability when structure is minimal (first trial or high demand) and when structure is high (second trial of low demand). The Zoo Map Test has been shown to have ecological validity and to be useful to detect planning impairment in alcoholics (Fernández-Serrano, Pérez-García, Perales, \& Verdejo-García, 2010; Moriyama et al., 2002).

Key Search subtest (BADS) (Wilson et al., 1996): Evaluates planning and strategy making skills. The 
participant is shown a square drawn on a piece of paper and is asked to imagine that it is a field. The subject's task is to draw a continuous line showing the path to follow to find the keys that have been lost at an unknown point in the field.

The Zoo Map and Key Search tests assess planning and have shown an adequate correlation with other measures of planning (Strauss, Sherman, \& Spreen, 2006). Diverse studies have shown that the BADS is an adequate battery of tests to evaluate executive functions and that it has ecological validity (Allain et al., 2005; Bennett, Ong, \& Ponsford, 2005; Wilson et al., 1996).

Wisconsin Card Sorting Test-3 (WCST-3) (Robinson, Kester, Saykin, Kaplan, \& Gur, 1991). This is a short version of the WCST (Grant \& Berg, 1948) in which the subject has to match 64 cards, one by one, with one of the four stimulus cards placed in front of them. After each classification, the examiner indicates to the subject if the response in correct or incorrect. There are three classification principles (color, shape and number) that change, without prior warning, each time that the subject makes 10 consecutive correct matches. Unlike the original WCST, in which the color-shape- number sequence is repeated twice (so that the subject can match up to six categories), in the WCST-3 the task ends once the subject completes the sequence, or when all 64 cards have been used. Completed categories and perseverative responses were registered. The WCST assesses concept formation and reactive cognitive flexibility. Neuroimaging lesion studies have related adequate completion of this task with activation of the dorsolateral and medial prefrontal cortex (Buchsbaum, Greer, Chang, \& Berman, 2005).

\subsection{Statistical analyses}

The data were analyzed with SPSS, version 15.0 for Windows (SPSS, 2006).

To analyze the effect of $\mathrm{BD}$ and sex on neuropsychological performance were carried out univariate ANOVAs with two factors, each with two levels, for each of the dependent variables. Differences were considered significant at $\mathrm{p}<0.05$.

\section{Results}

\subsection{Binge drinking}

Statistical analysis revealed a significant effect of BD on performance of the Backward Digit Span test $[F(1,115)=6.816, \mathrm{p}=.01]$; BD subjects scored lower than non-BD subjects (Table 2 ).

\section{Table 2}


A significant effect of BD was too observed on the number of perseverations of the SOPT $[\mathrm{F}(1,118)$ $=6.474, \mathrm{p}=.012]$. As a group, BD subjects produced more perseverations than non-BD subjects.

\subsection{Binge drinking by Sex}

A significant interaction BD by Sex was observed in Backward Digit Span $[F(1,115)=4.945, p=$ $.028]$. Male BD obtained lower scores than non-BD males $(\mathrm{p}=.001)$ and females BD $(\mathrm{p}=.041)$.

\subsection{BD without occasional consumption of cannabis}

To be sure that difference in occasional cannabis consumption among the groups was not confounding the results, we conducted a second analysis excluding these participants.

The results confirm the significant effect of BD on performance of the Backward Digit Span Test $[F(1,80)=5.884, p=.018]$ and on the number of perseverations of SOPT $[F(1,81)=7.344, p=.008]$. Besides, the differences on total errors of the SOPT achieved statistical significance $[F(1,82)=3.998$, $\mathrm{p}=.049]$.

By contrast, the analysis did not show significant interaction effect of BD by Sex on Backward Digit Span Test $[\mathrm{F}(1,80)=1.535, \mathrm{p}=.219]$.

\section{Discussion}

The main objective of this study was to analyze the association between BD pattern of alcohol consumption and executive functions in young university students. The sample consisted of first year students with no other relevant risk factors (such as psychiatric comorbidity, family history of alcoholism or polyconsumption of drugs). A further aim of the study was to determine if sex modulates the association between BD and neuropsychological performance.

As regards the first objective, the data show that in comparison with non-BD subjects, the $\mathrm{BD}$ university students obtain significantly lower scores in the Backward Digit Span test and commit more perseveration errors in the SOPT. These differences remained significant when analyzing the data excluding participants who have occasional consumption of cannabis.

The poorer performance of the BD subjects in the Backward Digit Span test indicates a lower capacity to retain and manipulate information in verbal working memory. The pattern of performance of the Spatial Span test was similar to the Backward Digit Span Test, although in this case the differences 
between groups were not significant $(\mathrm{p}=0.065)$. Both tasks require manipulation of information in working memory, rather than the simple retention required in the Forward Digit Span and Forward Spatial Span subtests. According to the working memory model of Baddeley (2003), performance will depend to a greater extent on the central executive component than on the phonological loop or on the visuospatial sketchpad. The central executive to engage multiple brain regions in a functionally coherent network, which includes the dorsolateral prefrontal cortex.

The BD subjects also displayed difficulties in another task involving executive aspects of working memory. They commit more perseverations in the SOPT, a task that measures an individual's ability to monitor a set of self-generated responses within working memory. For successful performance it is not sufficient to retain the information in working memory, but the information must be carefully monitored. Thus, the errors may reflect difficulties in supervision of the strategy used to resolve the task. Lesion studies in monkeys, and lesion and functional neuroimaging studies in human subjects have shown that performance of the SOPT is associated with activity in Brodmann's Areas 46 and 9 in the mid-dorsolateral prefrontal cortex (Petrides, 1995; Petrides \& Milner, 1982; Petrides et al., 1993).

There were no differences between the groups in terms of cognitive flexibility and planning. The capacity to generate new responses, measured by verbal fluency in the Letter Fluency test, to plan an action, assessed by Zoo Map and Key Search of BADS, and to form concepts and to adapt the behavior to external contingencies, evaluated by the WCST-3 test, did not differ in relation to the pattern of alcohol consumption.

These results partly confirm our hypothesis as they show that the BD students perform less well in tasks that involve executive skills that depend on the functional integrity of the prefrontal cortex. To date, few studies have analyzed neuropsychological performance in adolescents from the general population in tests of executive functioning. Their results are consistent with those of the present study. Hartley et al. (2004) compared BD and non-BD university students, and observed that the young BD performed significantly less well in planning tests (they took longer to plan an action in the Stockings of Cambridge test) and in attention/working memory tests (they obtained fewer correct responses in the PASAT), which the authors attributed to differences in executive skills. In other study with university students of between 18 and 20 years old (García-Moreno et al., 2008; GarcíaMoreno et al., 2009), the authors showed that the young BD committed more perseverations and intrusion errors in the free recall test of the TAVEC, and generated more false positives in the recognition test in the same trial; they displayed greater interference in the Stroop test, and performed less well in the Digit Span test of the WMS-III, in Corsi's Cube test and in the Series Recall test. Although backward and forward recall were not assessed in the Digit Span test and Corsi's Cube test (and therefore the authors could not determine whether there were differences in executive aspects of the working memory), the poorer performance of the Series Recall test (in which during $30 \mathrm{~s}$ the 
subject has to subtract 7 and then add 3 to a 3 digit number given by the researcher, and verbalize the result of each operation) may be interpreted as being due to difficulties in manipulating information in the verbal working memory.

Regarding our second objective was hypothesized, based on studies with alcoholics and adolescents with AUD, those BD women would show greater cognitive difficulties than men BD. Our findings do not support this hypothesis. In general, we did not observe any interactions between BD and sex, with one exception. The BD males performed less well in the Backward Digit Span test than BD females and non BD males, although this difference disappeared when the analysis excluded subjects with occasional use of cannabis.

Sex-differences in brain alcohol-induced effects have not been widely studied in BD adolescents. Hartley et al. (2004) did not find any sex differences in executive functions in young healthy undergraduates. Nederkoorn et al. (2009) reported that female, but not male BD, had less inhibitory control than non-BD subjects. They consider that the inhibition-related problem is a premorbid factor for heavy drinking in women. Studies with young social drinkers with a BD pattern of alcohol consumption found that BD females, but not BD males, performed less well in a cognitive flexibility task and committed more commission errors in an inhibitory control task (Scaife \& Duka, 2009; Townshend \& Duka, 2005; Weissenborn \& Duka, 2003).

These results are not consistent with those obtained in the present study. It is possible that the difference in populations studied may explain the findings, and that alcohol-specific deficits in executive abilities only appear in subjects with a longer history of alcohol consumption or a more severe pattern of consumption. In fact, Townshend and Duka (2005) attributed observed sex differences to the characteristics of the pattern of consumption in the women in the sample under study. Specifically, the sex differences in the spatial working memory task had not been observed in a previous study in which the females had lower alcohol scores. Again, further longitudinal studies specifically addressing this question would help clarify the role of sex in this question.

In summary, the present results show that the BD pattern of alcohol consumption is associated with poorer performance of tasks that require executive skills which have been related to functioning of the dorsolateral prefrontal cortex. Specifically, the young BD students showed greater difficulties in executive control of working memory. These findings do not appear to correspond to differences between groups as regards their premorbid intellectual level, academic performance, family socioeconomic level, polyconsumption of drugs or family history of alcoholism and psychopathology, variables that were controlled for during sample selection. Also, this relationship does not appear to be modulated by sex. Our findings do not support enhanced vulnerability of women to alcohol neurotoxic effects. 
In the adult population, studies carried out with chronic adult alcoholics show that the frontal cortex is particularly vulnerable to the neurotoxic effects of alcohol (Oscar-Berman \& Marinkovic, 2007). If to this greater vulnerability we add the fact that the prefrontal cortex is one of the last regions to develop fully, with an important degree of improvement during adolescence in more complex executive functions (Conklin et al., 2007; Luciana \& Nelson, 2002; Luna et al., 2010; Rubia et al., 2000; Salatas-Waters, 1982; Welsh et al., 1991), it is possible that this brain region may be more susceptible to the effects of alcohol during adolescence and early adulthood.

The more complex executive skills show a different maturation during the adolescence. Developmental studies showed that working memory appear to reach mature levels at 16-19 years of age (De Luca \& Leventer, 2008). These differences observed between BD and nonBD may therefore responded to a delay in development. This hypothesis must be tested in future longitudinal studies.

Caution must be taken as regards interpreting the association between BD and difficulties in executive functions as a causal relationship. Because of the cross-sectional nature of this study, the directional and developmental relationship of executive abilities and alcohol use cannot be clearly ascertained. Longitudinal studies examining the developmental trajectories of male and female adolescents will help clarify these associations. Secondly, given the academic background and the extensive exclusionary criteria, this sample may reflect a fairly high functioning sample within the population of BD adolescents. Therefore, the results may not be applicable to adolescents with significant comorbid polydrug use or psychiatric disorders. Finally, we do not have available neuroimaging data for the subjects, so that the anatomical-function relationships suggested must be viewed cautiously.

\section{Role of funding sources}

Funding for this study was provided by Consellería de Innovación e Industria of Xunta de Galicia, grant number PGIDIT05CS021103PR and INCITE08PXIB211015PR, by Plan Nacional sobre Drogas of Ministerio de Salud y Consumo of Spain, grant number 2005/PN014, and by Ministerio de Ciencia e Innovación of Spain, grant number EDU2008-03440. None of them had no role in the study design, collection, analysis or interpretation of the data, writing the manuscript, or the decision to submit the paper for publication.

\section{Contributors}

Authors Montserrat Corral, Socorro Rodríguez Holguín and Fernando Cadaveira designed the study and wrote the protocol. Authors María Parada and Montserrat Corral managed the literature searches 
and summaries of previous related work. Authors Alberto Crego, Nayara Mota and María Parada collected data. Author María Parada undertook the statistical analysis, and wrote the first draft of the manuscript. All authors reviewed and have approved the final manuscript.

\section{Conflict of interest}

All authors declare that they have no conflicts of interest.

\section{Acknowledgments}

This research was financially supported by Consellería de Innovación e Industria of Xunta de Galicia, grant number PGIDIT05CS021103PR and INCITE08PXIB211015PR, by Plan Nacional sobre Drogas of Ministerio de Salud y Consumo of Spain, grant number 2005/PN014, and by Ministerio de Ciencia e Innovación of Spain, grant number EDU2008-03440.

\section{References}

Acker, C. (1986). Neuropsychological deficits in alcoholics: The relative contributions of gender and drinking history. British Journal of Addiction, 81, 395-403.

Allain, P., Nicoleau, S., Pinon, K., Etcharry-Bouyx, F., Barré, J., Berrut, G., et al. (2005). Executive functioning in normal aging: A study of action planning using the Zoo Map Test. Brain and Cognition, 57, 4-7.

Artiola I Fortuny, L., Hermosillo-Romo, D., Heaton, R. K., \& Pardee, R. E. (1999). Manual de normas y procedimientos para la batería neuropsicológica en español. Arizona: $\mathrm{m}$ Press.

Baddeley, A. (2003). Working memory: Looking back and looking forward. Nature Reviews, 4, 829839.

Bennett, P. C., Ong, B., \& Ponsford, J. (2005). Assessment of executive dysfunction following traumatic brain injury: Comparison of the BADS with other clinical neuropsychological measures. Journal of the International Neuropsychological Society, 11, 606-613.

Blakemore, S. J., \& Choudhury, S. (2006). Development of the adolescent brain: Implications for executive function and social cognition. Journal of Child Psychology and Psychiatry, 47, 296-312.

Buchsbaum, B. R., Greer, S., Chang, W. L., \& Berman, K. F. (2005). Meta-analysis of neuroimaging studies of the Wisconsin card-sorting task and component processes. Human Brain Mapping, $25,35-45$.

Caamaño-Isorna, F., Corral, M., Parada, M., \& Cadaveira, F. (2008). Factors associated with risky consumption and heavy episodic drinking among Spanish university students. Journal of Studies on Alcohol and Drugs, 69, 308-312. 
Caldwell, L. C., Schweinsburg, A. D., Nagel, B. J., Barlett, V. C., Brown, S. A., \& Tapert, S. F. (2005). Gender and adolescent alcohol use disorders on BOLD (blood oxygen level dependent) response to spatial working memory. Alcohol and Alcoholism, 40, 194-200.

Casey, B. J., Jones, R. M., \& Hare, T. A. (2008). The adolescent brain. Annals of the New York Academy of Sciences, 1124, 111-126.

Chun, T. H., Spirito, A., Hernández, L., Fairlie, A. M., Sindelar-Manning, H., Eaton, C. A., et al. (2010). The significance of marijuana use among alcohol-using adolescent emergency department patients. Academic Emergency Medicine, 17, 63-71.

Conklin, H. M., Luciana, M., Hooper, C. J., \& Yarger, R. S. (2007). Working memory performance in typically developing children and adolescents: Behavioral evidence of protracted frontal lobe development. Developmental Neuropsychology, 31, 103-128.

Courtney, K. E., \& Polich, J. (2009). Binge drinking in young adults: Data, definitions, and determinants. Psychological Bulletin, 135, 142-156.

Crego, A., Rodríguez Holguín, S., Parada, M., Mota-Miranda, M., Corral, M., \& Cadaveira, F. (2010). Reduced anterior prefrontal cortex activation in young binge drinkers during a visual working memory task. Drug and Alcohol Dependence, 109, 45-56.

Crews, F., \& Boettiger, C. A. (2009). Impulsivity, frontal lobes and risk for addiction. Pharmacology, Biochemistry, and Behavior, 93, 237-247.

Crews, F. T., Braun, C. J., Hoplight, B., Switzer, R. C., \& Knapp, D. J. (2000). Binge ethanol consumption causes differential brain damage in young adolescent rats compared with adult rats. Alcoholism, Clinical and Experimental Research, 24, 1712-1723.

Curtis, C. H., Zald, D. H., \& Pard, J. V. (2000). Organization of working memory within the human prefrontal cortex: A PET study of self-ordered object working memory. Neuropsychologia, $38,1503-1510$.

De Bellis, M. D., Narasimhan, A., Thatcher, D. L., Keshavan, M. S., Soloff, P., \& Clark, D. B. (2005). Prefrontal cortex, thalamus, and cerebellar volumes in adolescents and young adults with adolescent-onset alcohol use disorders and comorbid mental disorders. Alcoholism, Clinical and Experimental Research, 29, 1590-1600.

De Luca, C. R., \& Leventer, R. J. (2008). Developmental trajectories of executive functions across the lifespan. In V. Anderson, R. Jacobs, \& P. Anderson (Eds.), Executive functions and the frontal lobes. A lifespan perspective (pp. 281-304). New York: Psychology Press.

Degenhardt, L., Hall, W., \& Lynskey, M. (2001). The relationship between cannabis use and other substance use in the general population. Drug and Alcohol Dependence, 64, 319-327.

Degoratis, L. R. (1983). SCL-90-R. Administration, scoring and procedures manual II for the revised version of the SCL-90-R. Baltimore: John Hopkins University Press.

Falk, D., Yi, H., \& Hiller-Sturmhöfel, S. (2008). An epidemiological analysis of co-occurring alcohol and drug use and disorders. Findings from the national epidemiologic survey of alcohol and related conditions (NESARC). Alcohol Research \& Health, 31, 100-110.

Fernández-Serrano, M. J., Pérez-García, M., Perales, J. C., \& Verdejo-García, A. (2010). Prevalence of executive dysfunction in cocaine, heroin and alcohol users enrolled in therapeutic communities. European Journal of Pharmacology, 626, 104-112.

Frith, C. D., Friston, K. S., Liddle, P. F., \& Frackowlak, R. S. (1991). A PET study of word finding. Neuropsychology, 14, 353-360.

García-Moreno, L. M., Expósito, J., Sanhueza, C., \& Angulo, M. T. (2008). Actividad prefrontal y alcoholismo de fin de semana en jóvenes. Adicciones, 20, 271-279.

García-Moreno, L. M., Expósito, J., Sanhueza, C.,\& Gil, S. (2009). Rendimiento cognitivoy consumo de alcohol durante los fines de semana en mujeres adolescentes. Neuropsicología, 
Neuropsiquiatria y Neurociencias, 19, 75-91.

Glenn, S. W., \& Parsons, O. A. (1992). Neuropsychological efficiency measures in male and female alcoholics. Journal of Studies on Alcohol, 53, 546-552.

Gogtay, N., Giedd, J. N., Lusk, L., Hayashi, K. M., Greenstein, D., Vaituzis, A. C., et al. (2004). Dynamic mapping of human cortical development during childhood through early adulthood. Proceeding of the National Academy of Sciences, 101, 8174-8179.

Gourovitch, M. L., Kirkby, B. S., Goldberg, T. E., Weinberger, D. R., Gold, J. M., Esposito, G., et al. (2000). A comparison of rCBF patterns during letter and semantic fluency. Neuropsychology, $14,353-360$.

Grant, D. A., \& Berg, E. A. (1948). A behavioural analysis of degree of reinforcement and ease of shifting to new responses in a weigl-type card-sorting problem. Journal of Experimental Psychology, 38, 401-411.

Guerri, C., \& Pascual, M. (2010). Mechanisms involved in the neurotoxic, cognitive, and neurobehavioral effects of alcohol consumption during adolescence. Alcohol, 44, 15-26.

Hartley, D. E., Elsabagh, S., \& File, S. E. (2004). Binge drinking and sex: Effects on mood and cognitive function in healthy young volunteers. Pharmacology, Biochemistry, and Behavior, 78, 611-619.

Henry, J. D., \& Crawford, J. R. (2004). A meta-analytic review of verbal fluency performance following focal cortical lesions. Neuropsychology, 18, 284-295.

Hommer, D. W. (2003). Male and female sensitivity to alcohol-induced brain damage. Alcohol Research \& Health, 27, 181-185.

Hommer, D. W., Momenan, R., Kaiser, E., \& Rawlings, R. R. (2001). Evidence for a gender-related effect of alcoholism on brain volume. The American Journal of Psychiatry, 158, 198-204.

Luciana, M., \& Nelson, C. A. (2002). Assessment of neuropsychological function through use of the Cambridge Neuropsychological Testing Automated Battery: Performance in 4- to 12-year-old children. Developmental Neuropsychology, 22, 595-624.

Luna, B., Padmanabhan, A., \& O'Hearn, K. (2010). What has fMRI told us about the development of cognitive control through adolescence? Brain and Cognition, 72, 101-113.

Mann, K., Ackermann, K., Croissant, B., Mundle, G., Nakovics, H., \& Diehl, A. (2005). Neuroimaging of gender differences in alcohol dependence: Are women more vulnerable? Alcoholism, Clinical and Experimental Research, 29, 896-901.

Medina, K. L., McQueeny, T., Nagel, B. J., Hanson, K. L., Schweinsburg, A. D., \& Tapert, S. F. (2008). Prefrontal cortex volumes in adolescents with alcohol use disorders: Unique gender effects. Alcoholism, Clinical and Experimental Research, 32, 386-394.

Moriyama, Y., Mimura, M., Kato, M., Yoshino, A., Hara, T., Kashima, H., et al. (2002). Executive dysfunction and clinical outcome in chronic alcoholics. Alcoholism, Clinical and Experimental Research, 26, 1239-1244.

Nederkoorn, C., Baltus, M., Guerrieri, R., \& Wiers, R. W. (2009). Heavy drinking is associated with deficient response inhibition in women but not in men. Pharmacology, Biochemistry, and Behavior, 93, 331-336.

Obernier, J. A., White, A. M., Swartzwelder, H. S., \& Crews, F. T. (2002). Cognitive deficits and CNS damage after a 4-day binge ethanol exposure in rats. Pharmacology, Biochemistry, and Behavior, 72, 521-532.

Oscar-Berman, M., \& Marinkovic, K. (2007). Alcohol: Effects on neurobehavioral functions and the brain. Neuropsychology Review, 17, 239-257.

Pascual, M., Blanco, A. M., Cauli, O., Miñarro, J., \& Guerri, C. (2007). Intermittent ethanol exposure 
induces inflammatory brain damage and causes long-term behavioural alterations in adolescent rats. The European Journal of Neuroscience, 25, 541-550.

Pascual, M., Boix, J., Felipo, V., \& Guerri, C. (2009). Repeated alcohol administration during adolescence causes changes in the mesolimbic dopaminergic and glutamatergic systems and promotes alcohol intake in the adult rat. Journal of Neurochemistry, 108, 920-931.

Petrides, M. (1991). Functional specialization within the dorsolateral frontal cortex for serial order memory. Proceedings of the Royal Society of London Series B-Biological Sciences, 23, 299306.

Petrides, M. (1995). Impairments on nonspatial self-ordered and externally ordered working memory tasks after lesions of the mid-dorsal part of the lateral frontal cortex in the monkey. The Journal of Neuroscience, 15, 359-375.

Petrides, M., Alivisatos, B., Evans, A. C., \& Meyer, E. (1993). Dissociation of human middorsolateral from posterior dorsolateral frontal cortex in memory processing. Proceedings of the National Academy of Sciences of the United States of America, 90, 829-839.

Petrides, M., \& Milner, B. (1982). Deficits on subject-ordered tasks alter frontal and temporal lobe lesions in man. Neuropsychologia, 20, 249-262.

Phelps, E. A., Hyder, F., Blamire, A. M., \& Shulman, R. G. (1997). FMRI of the prefrontal cortex during overt verbal fluency. Neuroreport, 8, 561-565.

Robinson, L. J., Kester, D. B., Saykin, A. J., Kaplan, E. F., \& Gur, R. C. (1991). Comparison of two short forms of the Wisconsin Card Sorting Test. Archives of Clinical Neuropsychology, 6, 2733.

Ross, T. P., Hanouskova, E., Giarla, K., Calhoun, E., \& Tucker, M. (2007). The reliability and validity of the self-ordered pointing task. Archives of Clinical Neuropsychology, 22, 449-458.

Rubia, K., Overmeyer, S., Taylor, E., Brammer, M., Williams, S. C., Simmons, A., et al. (2000). Functional frontalisation with age: Mapping neurodevelopmental trajectories with fMRI. Neuroscience and Biobehavioral Reviews, 24, 13-19.

Salatas-Waters, H. (1982). Memory development in adolescence: Relationships between metamemory, strategy use, and performance. Journal of Experimental Child Psychology, 33, $183-195$.

Scaife, J. C., \& Duka, T. (2009). Behavioural measures of frontal lobre function in a population of young social drinkers with binge drinking pattern. Pharmacology, Biochemistry, and Behavior, 93, 354-362.

Schulteis, G., Archer, C., Tapert, S. F., \& Frank, L. R. (2008). Intermittent binge alcohol exposure during the periadolescent period induces spatial working memory deficits in young adult rats. Alcohol, 42, 459-467.

Sowell, E. R., Thompson, P. M., Tessner, K. D., \& Toga, A. W. (2001). Mapping continued brain growth and gray matter density reduction in dorsal frontal cortex: Inverse relationships during postadolescent brain maturation. The Journal of Neuroscience, 21, 8819-8829.

SPSS (2006). Advanced statistics 15.0. Chicago: SPSS Inc.

Stephens, D. N., \& Duka, T. (2008). Cognitive and emotional consequences of binge drinking: Role of amygdala and prefrontal cortex. Proceedings: Biological Sciences, 12, 3169-3179.

Strauss, E., Sherman, E. M. S., \& Spreen, O. (2006). A compendium of neuropsychological tests: Administration, norms and commentary (3rd Ed.). New York: Oxford University Press.

Sullivan, E. V., Fama, R., Rosenbloom, M. J., \& Pfefferbaum, A. (2002). A profile of neuropsychological deficits in alcoholic women. Neuropsychology, 16, 74-83.

Tapert, S. F., Baratta, M. V., Abrantes, A. M., \& Brown, S. A. (2002). Attention dysfunction predicts 
substance involvement in community youths. Journal of the American Academy of Child and Adolescent Psychiatry, 41, 680-686.

Tapert, S. F., \& Brown, S. A. (1999). Neuropsychological correlates of adolescent substance abuse: Four-year outcomes. Journal of the International Neuropsychological Society, 5, 481-493.

Tapert, S. F., Brown, G. G., Kindermann, S. S., Cheung, E. H., Frank, L. R., \& Brown, S. A. (2001). fMRI measurement of brain dysfunction in alcohol-dependent young women. Alcoholism, Clinical and Experimental Research, 25, 236-245.

Townshend, J. M., \& Duka, T. (2005). Binge drinking, cognitive performance and mood in a population of young social drinkers. Alcoholism, Clinical and Experimental Research, 29, $317-325$.

Varela, J., Braña, T., Real, E., \& Rial, A. (2005). Validación empírica do AUDIT (Cuestionario de Identificación dos Trastornos debido ó consumo de alcohol) na poboación xeral galega. Santiago de Compostela: Xunta de Galicia. Consellería de Sanidad-Sergas.

Vicki, M., Kuntsche, E., \& Gmel, G. (2010). Drinking at European universities? A review of students' alcohol use. Addictive Behaviors, 35, 913-924.

Wechsler, D. (1997). Wechsler memory scale-III. San Antonio: The Psychological Corporation.

Weissenborn, R., \& Duka, T. (2003). Acute alcohol effects on cognitive function in social drinkers: Their relationship to drinking habits. Psychopharmacology, 165, 306-312.

Welsh, M. C., Pennington, B. F., \& Groisser, D. B. (1991). A normative-developmental study of executive in prefrontal function in children. Developmental Neuropsychology, 7, 131-149.

Wilson, B. A., Evans, J. J., Alderman, N., Burgess, P. W., Emslec, H., \& Evans, Y. (1996). Behavioral assessment of the dysexecutive syndrome. England: Thames Vallet Test Company.

Yurgelun-Todd, D. (2007). Emotional and cognitive changes during adolescence. Current Opinion in Neurobiology, 17, 251-257. 
Table 1. Mean ( \pm SD) for sociodemographic, clinical and alcohol use pattern characteristics.

\begin{tabular}{lcccc}
\hline & No binge drinking & \multicolumn{3}{l}{ Binge drinking } \\
\cline { 2 - 5 } & Males & Females & Males & Females \\
\hline $\mathrm{n}$ & 31 & 29 & 32 & 30 \\
Age & $18.61(0.55)$ & $18.83(0.53)$ & $19.03(0.53)$ & $18.70(0.59)$ \\
Hand-dominance (right/left) & $28 / 3$ & $28 / 1$ & $31 / 1$ & $28 / 2$ \\
Socio-economic status (low//medium/high) & $0 / 27 / 4$ & $4 / 22 / 3$ & $2 / 27 / 3$ & $3 / 19 / 7$ \\
Caucasian ethnicity (\%) & 100 & 100 & 100 & 100 \\
SCL-90-R (percentile GSI) & $55.00(28.83)$ & $41.72(25.57)$ & $60.50(31.86)$ & $37.83(26.96)$ \\
Vocabulary, scaled score (WAIS-III) & $12.65(2.27)$ & $12.52(1.74)$ & $12.59(1.43)$ & $11.57(1.50)$ \\
University entrance grade exam & $6.59(1.17)$ & $6.63(0.82)$ & $6.38(1.27)$ & $6.31(1.20)$ \\
Occasional use of cannabis & 2 & 7 & 14 & 13 \\
Tobacco smokers & 0 & 1 & 4 & 8 \\
Age of onset of regular consumption on alcohol* & $16.00(0.85)$ & $15.54(1.25)$ & $15.13(1.26)$ & $14.53(1.26)$ \\
Drinks in the last week b,* & $2.74(4.09)$ & $3.38(3.87)$ & $15.29(12.56)$ & $19.25(12.64)$ \\
Percentage of times became drunk when & $5.39(11.62)$ & $5.96(7.78)$ & $51.18(31.04)$ & $49.00(34.72)$ \\
drinking* & & & & \\
Times drunk in the last two weeks* & $0.03(0.18)$ & $0.26(0.71)$ & $2.04(1.82)$ & $1.86(2.03)$ \\
Speed of consumption: drinks per hour* & $0.65(1.14)$ & $1.14(0.99)$ & $3.41(1.38)$ & $3.29(0.76)$ \\
Total AUDIT score & $2.10(2.16)$ & $2.97(1.93)$ & $12.91(4.72)$ & $11.47(4.04)$ \\
\hline
\end{tabular}

Note: SCL-90-R (Symptom Checklist 90 Revised); GSI (Global Severity Index); WAIS-III (Wechsler Adult Intelligence Scale-III); AUDIT (Alcohol Use Disorder Identification Test).

a Less than 10 occasions per year.

b Self-reported.

$* \mathrm{p}<0.001$ significant differences between groups. 
Table 2. Mean $( \pm$ SD) scores for the neuropsychological tests.

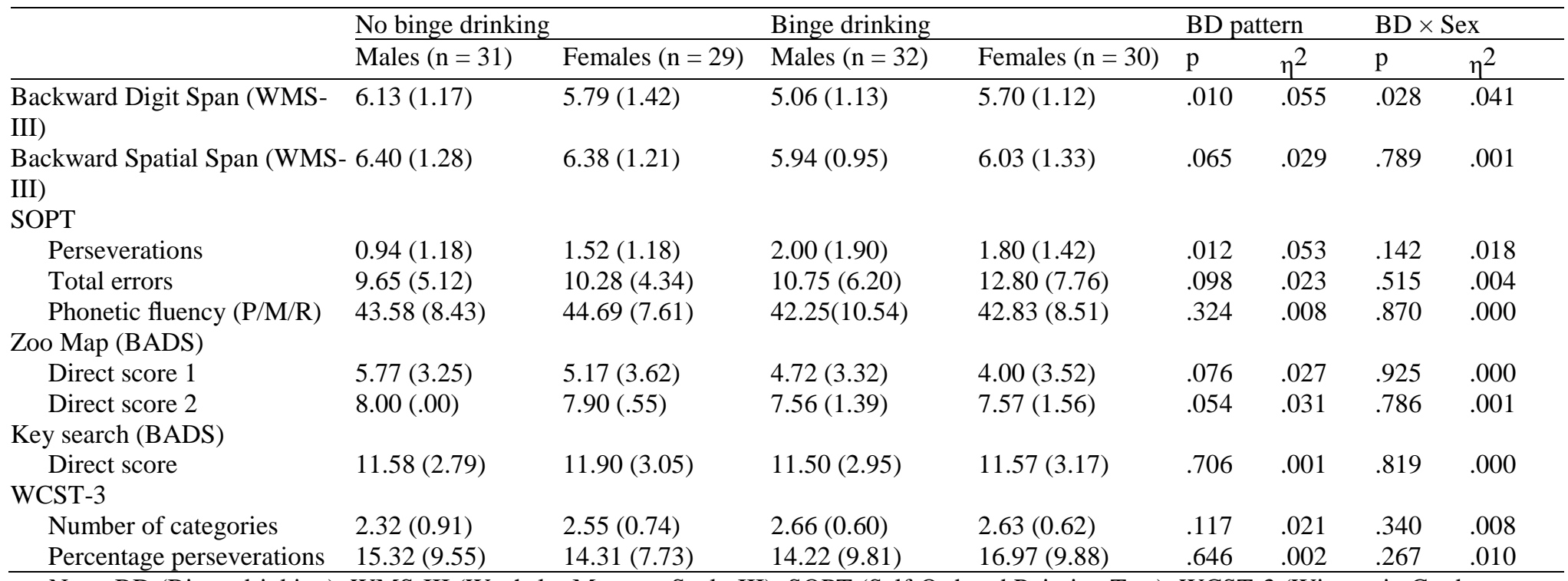

Note: BD (Binge drinking); WMS-III (Wechsler Memory Scale-III); SOPT (Self-Ordered Pointing Test); WCST-3 (Wisconsin Card Sorting Test-3); BADS (Behavioral Assessment of Dysexecutive Syndrome) 